\title{
Struggles of Professionalism and Emotional Labour in Standardized Mental Health Care
}

\section{Annette Kamp'}

Assoc. Professor, PhD, Centre for Working Life Research, Department of Environmental, Social and Spatial Change, Roskilde University, Denmark

\section{Betina Dybbroe}

Professor, PhD, Centre for Health Promotion Research, Department of Psychology and Educational Studies, Roskilde University, Denmark

\begin{abstract}
This article points out how recent public sector reforms under headings as New Public Management, Lean and Quality Reforms entail different forms for standardization, and examines how this development instigates a transformation of interdisciplinary and highly skilled emotional labor in mental healthcare. It is based on an ethnographic study of a Danish child psychiatric unit, which 'produces' diagnoses and treatment/therapy for children and their families. We illustrate how the enforcement of standardization upsets the balance between the humanistic and medical aspects of psychiatry as a discipline and field of practice, and show how this development challenges professional identities, interdisciplinary collaboration and hierarchical relations. The development is however negotiated, reformulated, and opposed, in teams of mental health professionals. In this context of increasing standardization, highly skilled emotional labor unfolds. We point out how acceleration and leaning of work procedures increases the emotional labor in relation to clients, partners, and colleagues. But paradoxically, at the same time, emotional labor becomes still more invisible as it is excluded from the standardized schemes. The study illustrates the crucial role of emotional labor in mental care work and points out how it is left to the professionals to negotiate paradoxes and make ends meet.
\end{abstract}

\section{KEY WORDS}

Interdisciplinary work / emotional labor / psychiatry / standardization

DOI

10.19154/njwls.v6il.4886

\section{Introduction}

ork in the public health sector in Denmark, as well as in other Nordic countries, has in the last 15-20 years undergone radical changes due to ongoing rationalization and market orientation under headings such as New Public Management, Quality reform, and Lean production (e.g. Bovbjerg, 2011; Christensen, 2012; Sahlin-Andersson, 1999). The ramifications of these reforms for healthcare professionals and their working life have been intensively debated. In particular, the position, status

\footnotetext{
${ }^{1}$ Annette Kamp, PhD, Centre for Working Life Research, Department of Environmental, Social and Spatial Change, Roskilde University, Building 08.2, 4000 Roskilde, Denmark, E-mail: kamp@ruc.dk
} 
and identities of the professionals, and their autonomy and possibility to exert professional assessment have been at focus (Hjort, 2001). Several studies explore how different groups of professionals experience ambiguity between a new managerial identity and the traditional care-oriented professional identity (Blomberg, 2003; Rasmussen, 2012). They also point out how professionals struggle and partly resist this development toward a market-oriented rationality, in some cases by taking on extra work in order to satisfy profession norms an standards, thus leading to self-intensification (Kirschhoff \& Karlsson, 2013; Rasmussen, 2004; Selberg, 2013), in other cases by reframing the new market-oriented ideas in order to make ends meet (Dahl, 2009). Also, the bureaucratic and tayloristic traits of the reforms are attended to, as they tend to undermine professional autonomy and meaningfulness (Dybbroe, 2012; Kamp, 2012; Kröger, 2011).

However, while these general insights are indeed valuable, we will argue that it important to scrutinize how these reforms are embedded into the specific fields within healthcare with their particular history, context, and practices. Thus, we will explore how ideas on the overall aim of work, configurations of professional groups, and organization of work are negotiated and resisted in ways that bear markings of traditions and experiences in the field.

In Denmark, work in mental healthcare is often organized in interdisciplinary teams comprising social, educational and care workers, nurses, psychologists, and psychiatrists, all involved in the work of diagnostics and treatment. Emotional labor is an ongoing part of work in mental health care that involves interaction with patients and their networks. It is a highly skilled and varied professional activity, where emotions are managed, processed, or contained, and may represent the very core of the job, or merely an element needed to 'get the job done'. We explore how this interdisciplinary and emotionally skilled work is practised and at the same time transformed through the different market-oriented reforms that have swept over the psychiatry in recent years, and how transformations of social relations and positions are instigated.

In studying these very complex processes, we focus on standardization, as this is one of the main measures used in these reforms in order to enable central management and control of work, quality, and output. New Public Management, for example, implies a division of sectors into different (economic) self-contained units, which 'sell to' and 'buy from' each other, and here standardization of services to enable counting and pricing and centrally controlling the units via contracts. Standardization of services thus becomes the political prerequisite for contract management and outsourcing (Busch et al., 2005; Greve, 2003, 2007).

Setting standards implies establishing a uniform description of a field. This might facilitate the division and intensification of work that characterize a neo-tayloristic work organization. But it also implies creating a specific vocabulary for work activities and for what is being accomplished through work, thus voicing and privileging particular forms of knowledge and practises, while silencing other forms (Timmermans \& Berg, 2003). These new uniform descriptions alongside experiences of working in new fragmented and disruptive organizations may transform ideas of professionalism and challenge professional identities, inter-professional relations, and positions in hierarchical professional institutions, such as in the health system (Evetts, 2011).

The ideal of interdisciplinarity is a specific dimension that characterizes professional work and professionalism in healthcare, but at the same time, it is extremely contested in practice (Zukas et al., 2012). The neo-liberal turn in welfare policies in the Nordic 
countries has, as mentioned above, generally questioned the authority of health professions, but the effect on interdisciplinary practises has been paradoxical. On the one hand, the health professions have become more focused on borders and boundaries between professions (Bradbury et al., 2008) and have tried to reconstruct professional narratives continuously in order to gain terrain. On the other hand, the health professions have become more responsive to a constant quest for inter-professional problemsolving that has evolved as part of public critique (Dahl, 2009; Wrede et al., 2008). In psychiatry, inter-professionalism and inter-disciplinary work are presented as egalitarian and harmonious (Kleinman, 2012). However, institutionalization of psychiatry inside hospital organizations has always privileged some professions, and notably, medical expertise, even before the 1950s, when medicine was quite inadequate and other methods and regimes had high legitimacy (Johansen, 2005).

Within psychiatry, the ideal of interdisciplinarity partly stems from systemic approaches to psychiatry, which together with psychoanalysis has influenced developments in psychiatry since the 1970 s, and has dominated child and youth psychiatry in Denmark, the rest of Scandinavia, and the UK (Donovan, 2002). The systemic approach considers mental illness as an expression of a disturbance in the patient's social system, that is, the social relations of the patient, rather than being solely a disease of the individual. This implies that both diagnostics and help/treatment must involve an examination and understanding of the patient's natural environment and the perception that the patient's network also plays a role in treatment. A variety of disciplines (social, educational, medical, and psychological) therefore need to cooperate in this approach to mental healthcare through teamwork.

The history of psychiatry is however paradoxically the story of a field or discipline that has struggled to become a full member of the medical family with all its specializations (Møllerhøj, 2008). Psychiatry has therefore also had to submit to the scientific rationales that prevail in medicine. One of the fundamental building blocks is a standardized diagnostic system that describes and categorizes abnormal mental conditions (Brinkmann, 2010). There are ongoing international efforts to develop a detailed diagnostic system, in the form of the DSM (Diagnostic and Statistical Manual of Mental Disorders), a tool for patient categorization by professionals. Patients are described in terms of their diagnosis, they are grouped into diagnoses, and this forms the basis of their treatment. This approach thus represents a very different and decontextualized view of patients, compared with a systemic or humanistic approach. The diagnostic system, which is constantly being refined and expanded, most recently with the publication of DSM 5 in 2013, provides the structure for present-day psychiatry (Simonsen \& Møhl, 2010).

The humanistic regard for the individual and the human being in its specific context competes with the rational medical diagnostic system. These contradictions create and maintain tension in mental healthcare; this is manifested in practical work and must constantly find solutions in compromises enabled by the field of practice. The major changes that the sector has undergone in recent years, all of which use standardization as one of their main instruments, challenge such compromises, encouraging a rationalist and medical rather than a humanistic and social science approach to psychiatry and its practice. In this article, we combine insight from different parts of sociology, the sociology of standardization, professions, and emotions. We examine key dimensions of the standardization of mental health work, showing how standardization is performed, and also re-interpreted and opposed, in teams of mental health professionals. We explore 
how this development influences professional identity and interdisciplinary collaboration, and the consequences for what counts as work and who counts the most in the team. Our case study of work in a child psychiatric unit illustrates how the enforcement of standardization upsets the balance between the humanistic and medical aspects of psychiatry as a discipline and field of practice. We focus especially on the emotional labor involved in encounters with clients and partners. Our purpose here is to examine how emotional labor unfolds in the context of increasing standardization.

This article is based on an ethnographic study of a child psychiatric unit, which 'produces' diagnoses and treatment/therapy for children and their families. We begin the article with a theoretical section, where we position ourselves and the study within theoretical discussions on standardization, emotional labor, and professional identity. This is followed by a presentation of our methodological approach. We then describe and characterize the various types of standardization introduced in psychiatry, especially in the specific unit included in our study. The empirical analysis focuses on the emotional processes involved in the work, and considers how they on the one hand represent an entirely different logic from standardization, but on the other hand are integrated into, and negotiated on the basis of, standardization requirements. The study illustrates how perceptions of what constitutes the core of the work give rise to negotiations and conflict, how social relations in interdisciplinary teams come under pressure, and how the emotional labor and its status are affected.

\section{Standardization and emotional labor - the theoretical basis}

This article draws on different currents within sociology. We begin with the 'sociology of standardization' (Timmermans \& Epstein, 2010). This tradition presents a broad view of standardization, pointing out how the term covers different ways of creating uniformity in a particular field. It can apply to terminological standards that aim to provide language for an exhaustive description of a field. Such language creates universes that allow for the description and evaluation of certain aspects of the work, while other aspects remain silent and unmeasurable, and thus disappear out of sight. Procedural standards specify how the work is to be performed, involving greater regulation of behavior and actions and thus affecting work organization. Performance standards set specifications for the outcome of the work and therefore for its quality and quantity.

Standardization not only implies fragmentation and uniformity or even monotony in work, but may also more profoundly challenge the norms and ethics of a profession, the core task and perceptions of good quality, and how it should be achieved. Thus, standardization might lead to erosion of a profession, as many critical readers have discussed (e.g. Dybbroe, 2008; Kamp \& Hvid, 2012; Liff \& Andersson, 2011; Rasmussen, 2004). But the consequences may be more complex, and several studies argue that we should focus on the transformation of professions and reconfiguration of relations between different groups. Timmermans and Berg (2003) illustrate how standardization technologies require professional activity in order to function. Standardization is thus not seen as a structure or a rationale that is implemented, but as a dynamic process that is subject to argument and negotiation.

Timmermans and Berg (2003) also point out how standardization technologies give certain groups new legitimacy by positioning them as experts, thus transforming 
the hierarchy of the organization. Similarly, Halford et al. (2010) illustrate how this technology establishes special spaces for the contribution of each occupational/ professional group in their case study of electronic patient records, thus implying a change in the hierarchical relation between them. But they also show how such technologies result in making certain parts of the work invisible.

In our analysis of standardization in psychiatry, we find examples of terminological, procedural, and performance standards. We examine how standardization challenges professional identity and the relationship between the professional groups, and we illustrate how standardization increasingly renders emotional labor invisible. Here, we see professional identity as a dynamic entity, formed not only through education in the traditional sense (in the Weberian understanding of professions), with its emphasis on specialized knowledge and professional ethics, but also reformulated and developed locally in interaction with work tasks, colleagues, and work organization, and colored by life-historical experience (Evetts, 2011; Olesen et al., 2001). Thus, we perceive the transformation process we observe in psychiatry as a negotiation of standardization and the rationales involved, and at the same time as subjective meaningful practice in relation to different professional identities and positionings.

Our conception of emotional labor is inspired by the emotional sociology, originally launched by Arlie Hochschild (Hochschild, 1983), who reserved the concept emotional labor for the exploitation and management of emotions in the labor process. This conception has been widely debated and criticized for the sharp distinction between emotions as surface acting and the 'authentic emotions', thus excluding the joy and meaningfulness of emotional labor (e.g. Bolton, 2005; Theodosius, 2012). Nancy Chodorow (Chodorow 1999), a cultural theorist inspired by psychodynamics, suggests that emotions at work must be understood as cultural mediations between an inner reality and an outer social reality and as such are not more or less authentic. Also, Sharon Bolton (Bolton, 2005) and Catherine Theodosius (2008) argue that emotions in the context of work and organizations are culturalized, but distinguish between different kinds of emotional scripts or rules. Bolton (2005) points out how employees may draw on several different regimes of management: The organizational or managerial regimes that aim at using emotionality to ensure maximum profitability, the professional regimes that develop emotional rules and scripts as part of establishing professional identities, and regimes that are formed by general socialization and support the more general social understandings of human interaction in specific contexts. Theodosius (2008), whose work particularly concerns emotional labor in healthcare, primarily focus on professional regimes, highlight how health professionals carry out emotional labor in order to support the execution of tasks, such as clinical investigations or counselling. But she also takes the attention to the emotional labor involved in negotiating collegial relations.

In our analysis, we focus on how emotional labor is carried out informed by professional regimes in psychiatry. We explore how emotional labor plays an important role in facilitating the execution of tasks, and also how managing emotions may in some instances be the principal task. Moreover, we, in line with Theodosius' insights, shed light on how emotional labor forms part of negotiating collegial relations, in particular in interdisciplinary teamwork, where different professional identities and paradigms are at play. An important part of this analysis is to highlight how the complex emotional labor involved in carrying out psychiatric assessments is negotiated within the frames of standardized psychiatry. 


\section{Methodology}

The analysis is based on empirical studies conducted over 2 years, starting in summer 2011, as part of a larger research project on work in psychiatry. The overall aim of the project was to study teamwork, which may (as in psychiatry) not only be rooted in the traditions of a particular field but also represents one of the modern ways of organizing self-management. We thus view teams as a field of tension that can not only create community and social support but also give rise to conflicts and stress. We have particularly focused on social relations in teams, and on meaning, identity, and well-being at work.

The general method is ethnographic field studies, where our approach has been 'multi-sited' (Marcus, 1995; Shore et al., 2011), as well as critical ethnographic (Madison, 2005) and institutional ethnographic (Smith, 2005). In the analysis, several concepts have been guiding the analysis: standardization, emotional labor, and professional identity. The methodology has been context sensitive and adapted to the object of research, that is, relational work between professionals and between clients and professionals, and it has been our guideline not to separate these interdependencies in the work we studied.

The work and the professionals' perspectives were explored by following various threads: studying certain employees during the entire working day, following a particular case or task, and following the process in a number of teams, both assessment and treatment teams. The choice depended on the context and practicalities. We followed the work of three teams, and five cases. In addition, we spent much time in the unit, attended staff meetings and took part in informal socialization during breaks, and so on. On five occasions, we also attended the so-called conferences, open meetings where everyone involved in a case took part to present and discuss the results of their work. In addition, we conducted six semi-structured qualitative interviews with employees in different professions. Here, we examined their professional life trajectories and their understandings of work, meaning, and identity, in order to illustrate how changes in mental health work are experienced and interpreted and affect meaning and well-being in their work. These interviews were later followed up with two focus group interviews with three to five participants. All interviews were transcribed just like all observations were documented by field notes, written at the site and completed - preferably - the same day.

\section{Standardization in psychiatry: NPM and lean in child psychiatry}

As in the rest of the Danish healthcare system, the 2000s saw the introduction of the purchaser-provider model in psychiatry. The basis of the model is an electronic catalogue of services built around the diagnosis-related group (DRG) system. This allows for the purchase and sale of services to be recorded and to form the basis for the finances of a particular unit or department. The catalogue is based on the logic that the client is the child and the main product received is a diagnosis. This is thus a terminological standard. It defines what counts as a service and lists a number of activities that contribute to the diagnosis. But only services that involve the child (the client) are counted, not services that only involve the parents, even though a number of the recognized tests are based on interviews with the parents alone. It is only possible to work within the system if the child has been given a diagnosis. Further, time may be divided into productive time - time that counts in the system - and unproductive time. Only services provided by 
nurses, doctors, and psychologists count, not the work of any other professional groups. This standardization technology means that part of the activities routinely performed in an assessment cannot be recorded as services. Services are defined quantitatively, through performance contracts, which include the number of services produced. The field is thus regulated by a number of performance standards. The quality of performance is primarily assessed on the basis of annual surveys of customer satisfaction.

A new Health Act in Denmark in 2005 allowed for freedom of choice of suppliers and enabled competition between public and private entities (Bovbjerg, 2011). At the same time, waiting time guarantees were introduced in mental healthcare. This led to pressure for reorganization and rationalization of work processes in psychiatry, and a comprehensive lean program was implemented to rationalize and reorganize the unit under study.

Such procedural standards determine, for example, how many diagnoses each team must produce per month. The 'lead time' for each 'client' is set at 2 months. Previously, the time spent on establishing the diagnosis varied considerably with the complexity of the case, and each team worked on several cases simultaneously. In the unit we have studied, the diagnostic teams have been reorganized. Previously, the teams were selforganized; one chose colleagues one preferred to work with, over an indefinite period of time. Now, however, the composition of the teams is determined by the management, and one must change partners every 3 months. The teams consist of two people, where a doctor or psychologist works with an educational therapist, nurse, or social worker. At the same time, the working day is now more strictly organized, being divided into assessment (diagnosis production) and treatment.

The Lean approach has thus to some extent led to a process standardization of the diagnostic work. The division of labor between the team members is not specified; it is agreed within the team on the basis of a professional assessment of the specific case and the interests and experience of the team members. But there are various tests that can only be administered by psychologists or doctors, while home visits and visits to the child's school or kindergarten can be undertaken by anyone. There are (so far) no standards for the types of tests or examinations to be performed in connection with an assessment. However, this will soon change with the introduction of so-called assessment packages in psychiatry; these will divide and construct psychiatric work in new ways (Danish Regions, 2011; Madsen et al., 2011).

Child psychiatry in Denmark was reformed during 2007-2009, with the introduction of the lean approach and greater focus on ambulatory and emergency treatment (Danish Regions, 2008) and this has also applied to the child psychiatric unit under study. The unit has a staff of about 30, including psychologists, doctors, educational therapists, nurses, and social workers, and has like other departments of the hospital a dual management team consisting of a senior doctor and a senior nurse.

\section{Work and professional hierarchies in transition}

\section{The dystopia: Psychiatry as a diagnosis industry}

In the first part of our analysis, we look more closely at how the strong focus on producing diagnoses and producing them effectively, as conveyed by the management 
technologies, were received by different professionals. The qualitative interviews reveal the role of assessment and diagnosis in the various professional groups' understanding of the core of their work, and show how standardization involves a reformulation of the goal of the work, which may be negotiated, adjusted, or rejected.

A psychologist has worked in a private child psychiatric unit for a few years and has experienced this market logic fully realized. He is quite clear and unambiguous in his view of current developments:

It's about the diagnosis rather than about the child. So there it was like: How many diagnoses did we do this week? Because that was what put was money in the till. And that's almost the way things are going now. I mean, we talk a lot about how many services we provided, how many assessments we did, because it counts. Tests and assessments lead to a diagnosis and a diagnosis leads to money. So I'm afraid we're beginning to lose the humanistic perspective, the child and the family become just a number in a list. (Simon, psychologist)

He continues:

In our profession it's more appropriate to tell a coherent story about a child. And to point out that there are very many factors, which can lead to a child appearing agitated and unfocused. Many other factors than ADHD. (Simon, psychologist)

At the same time, he explains how this 'diagnosis industry' challenges the inter-professional approach to work, where many dimensions of the children's lives are included. The different groups, that is, educational therapists, social workers, nurses, and psychologists, phrase their ideals differently, but all distance themselves from the 'diagnosis industry'. The diagnosis is acknowledged as the formal aim of their work, but its meaning is negotiated in different ways.

A psychiatric nurse says:

In reality I don't think it's so important what it's called [the diagnosis]. It's more about how the child can get some help afterwards. That's my opinion. So I don't care whether it's called one thing or the other. But, for the sake of the parents, to ensure they get more help in the future, they have to have a name for what's wrong with the child. Or else nothing will happen. That's the way things are in our society. (Janice, nurse)

So, in her view, the diagnosis is a means, not the aim, and in addition, the detailed distinctions between different diagnoses and subcategories are futile from her point of view. What she also highlights however is that the diagnosis is the only legitimate way to get a problem addressed. The diagnosis is the access point to resources.

A broader view on what work is about, and what should be accomplished through the work process, can be found among most professionals. Leo, an educational therapist, focuses on the families, and he underlines the importance of relating to them properly and supporting them.

I think we should treat these parents respectfully. Be really nice to them ... understand that they're doing their best. But also show it, even if they're ten minutes late ... be decent with them anyway. ... They come in thinking they're normal parents, and then they go out with a handicapped child. It's a real shock for them. (Leo, educational therapist) 
He does not find that shortening the time allotted to establish the diagnosis - one of the results of the lean approach - is particularly problematic. He would rather use extra time and energy in giving the parents a sensible alternative in order to qualify them better for their new and changed life as parents.

Here, he points out the importance of the emotional labor involved. This implies a particular way of relating to the parents and also a pedagogical process of teaching them new skills, new ways of dealing with their parenthood.

Another psychologist, Birgit, however underlines her own and her psychologist colleagues' diagnostic skills and their long experience in working with the diagnostic classification. She adds that she understands the establishment of a diagnosis as a process, a process that should prepare the parents for their future situation. So, the skills of organizing this process are very important. She and the others still work on enhancing their skills in order to manage the different kinds of complex and unpredictable situations involved in interacting with clients and/or their networks. However, she highlights the problem of time. While it might be seen as a blessing that the families can receive a diagnosis within 14 days from their first visit to the child psychiatry unit, it is indeed a mixed blessing. The process is too short, and sometimes they have to leave the parents in a deep crisis.

This analysis illustrates the different professional views on the production of diagnoses and their justification as a formal aim of the work. But the focus of work in the unit is generally by all perceived as supporting the families in the process they are going through, so highly skilled emotional labor is highlighted as important for professional identity.

\section{At the conference: Negotiating diagnoses and identities}

The increased focus on producing diagnoses also affects the position of the various groups involved in the work of the unit. In this part of the analysis, we look at how their discussions about diagnoses often lead to conflict; the issue may be how a case should be presented, or the question of what is good diagnostic work, or notably the positioning of the different disciplines.

The weekly conference where the teams present their cases to an audience consisting of colleagues and management is an important institution. Here, final decisions are made on how to close a case and what diagnosis to give a child. In this forum, the professionals present their arguments and also their doubts or questions.

An important question is how to arrive at a diagnosis: What counts and how much? Formally, on the basis of the system-theoretical paradigm in psychiatry, observations in the child's home and educational institution and talks with the parents count just as much as psychological and medical tests. But the increased focus on providing diagnoses challenges this parity. In the conference, different types of argument and 'evidence' are tested against each other.

At the same time, this is a place where relations and identities are continually negotiated. As discussed in our theoretical section, the professionals' identities are constructed on the basis of both educational background and also the skills they apply and the tasks they perform in specific contexts. The tools and methods used by the professionals therefore also affect how they are identified and their place in the hierarchy. Child psychiatric 
work is often divided, the tests being conducted by psychologists and doctors, whereas the other tasks could be performed by anyone and preferably in teams. But as time schedules are tight, these tasks tend to be undertaken by a social, educational or care worker, or nurse.

As Leo, an educational therapist, remarks:

When you're a blacksmith, you may have a poor hammer, but when you're a teacher, you don't have a poor method, you're a poor teacher! So it means if you have a conflict on a professional issue, then it soon becomes a personal matter. (Leo, educational therapist)

While some conferences run smoothly without controversy, there are also dramas. A psychologist explains:

There are easy cases. The team agrees that the boy suffers from ADHD - tests and observations point in the same direction - and now we go to the conference and present our evidence. There are seldom objections, and we feel a sense of relief. It was a good performance and everyone is happy and smiles and says: How clever you are; we've solved another case. And then we go on to the next case. (John, psychologist)

The more difficult cases create more discussion and reveal dividing lines and conflicts.

In one case presented by Lena, a recently graduated doctor, and Janice, a nurse, the tests fail to support any diagnosis. Janice, the nurse, then reveals the child's very complex history. She describes the girl as an anxious child, having problems with sleep and food. There have been tragic events in the family. The mother's behavior toward her daughter does not seem adequate and so on.

A long discussion ensues. The colleagues show signs of impatience. 'What do you think, in terms of a diagnosis?' one of the psychologists asks rather sharply. Another colleague follows up: 'What do you want to achieve by bringing this case to the conference? Obviously you haven't finished your job'.

Lena and Janice come up with a proposal for a diagnosis, although unconvincingly. Some of the more experienced colleagues come to the rescue, and propose that a very competent psychologist should assist the team in further investigations, and management agrees that the (tight) timetable must be suspended. After the conference, Janice feels attacked and demeaned. She reflects:

Sometimes, it's quite difficult, when you have a case you've been so closely involved in. You and your teammate know almost every detail in it. And then you're supposed to present it at a conference! You can't include all the details. You just can't communicate all those small sensations and peculiarities you experience, when you spend time with this particular family ... So what do you do? Because sometimes these sensations and peculiarities are precisely what determine your descriptions and assessments. (Janice, nurse)

Several of the professionals described how it becomes difficult for them to make room for illuminating the results of their observations more in depth, in particular when the observations did not simply confirm test results, or directly go against them, and therefore needed to be unfolded in more details. This conference illustrates how test results are much easier to present than observations and interviews. The test results can easily 
be aggregated to clear answers and often play a dominant role in the decision-making. Tests are always presented by the psychologists or the psychiatrists. The form of these presentations emphasizes hard data and facts. The observations, on the contrary, are presented by the other team member, for example, a nurse or educational therapist, and are often quite descriptive and multifaceted focusing, for example, on the child's behavior in school, her interaction with other children, and so on.

Caroline, a social worker, remarks:

Tests take up a lot of room at the conference, and we talk less of the clinical picture than we did before. Maybe it is because the tempo is increasing. It is so much easier to talk about numbers. (Caroline, social worker)

As time pressure has increased, discussions characterized by ambiguity and insecurity are often sources to frustration. So, there is a widespread critique of conferences with too much loose talk that does not lead anywhere.

As there is a lack of experienced doctors in the unit, the psychologists have a leading role. Birgit, one of them, explains that the psychologists are best at DRG, having intimate knowledge of the system. When observing a conference, it is clear that this competence plays an important role.

Often, when a case is presented and a diagnosis is proposed, questions like: 'What do you think about using 83.2 instead of 83.1, have you ruled out that diagnosis?' are raised. This obviously excludes a large part of the audience. The doctors and the psychologists - and a few others - always bring the DRG booklet to the conferences. It is there in front of them and is used several times, and all those who have the booklet thumb through the pages.

In summary, the focus on diagnostics and the intrusion of medical vocabularies and ways of thinking, and the new emphasis on flow and time saving, tend to undermine the position of the professional groups such as educational therapists, social workers, and nurses. Their contributions - which are crucial for maintaining the social psychology approach - are devalued, and this is clearly displayed in their performance at the conferences, where they risk finding themselves in vulnerable and problematic positions.

\section{Working in a diagnostic team: Meaning and emotion management in the meeting with vulnerable families}

The following analysis examines team work in relation to the clients/patients, as practice and materiality: What is the work really about? How does this create meaning and is given meaning by professionals? As introduced in the methodology above, we also ask: how does emotionality in relation to a work with people, patients, and colleagues come into work? And, how does emotional labor interact with the standardization processes?

We apply emotional labor as a theoretical perspective in order to study how emotionality is managed and how it supports professionals' ways of practicing tasks, in relation to professional identifications with both a humanistic and a medical diagnostic paradigm. We analyse this in relation to standardization as a framing description of the field of work and as a concept, influencing procedures as well as performance. 
We have followed a sequence of intersubjective spaces, where most of the work takes place. Here, we present a case typical of child psychiatry, where a child has been admitted for assessment, and during a 3 to 4-week period, the two professionals Simon, the psychologist, and Carl, the social worker, work with observations in the context of the clients, discuss these in team meetings, perform tests, present their analysis to the parents, and eventually hold a meeting for the professional and familial network around the child.

The formalized goal of the work is to create a diagnostic assessment that may form the basis for further treatment and support of the patient (child) and her/his family. This assessment has to be legitimized both professionally and institutionally, and the professionals are to guarantee this through team work and the conference, as seen in the previous case. The diagnostic work needs to be completed, not when the professionals judge that they have done a satisfactory job, but by a specific time prescribed by the standards. However, the standards are not entirely unambiguous, since the performance standardization is based on customer satisfaction, which plays a major role in local and regional political reality. It also plays an important role for the professionals, who can gain significant feedback on their work from user surveys and who can connect their work experiences to the statistics to which they often refer. In this case, we see that the two professionals have a number of goals, and the final goal is different from the diagnosis.

Since 2010, the standards have included a long list of forms of consumer satisfaction that have to be taken into account by the professionals, as the statistics are monitored by top management, and dissatisfaction could create political problems for the unit as a whole. Professional performances are measured by consumer satisfaction on specific standards such as waiting time. Two months is the limit they can work in, from the initial admission of a child for assessment until a plan for treatment and intervention has been drawn up (Health Plan, 2010). In the sector we have studied, the internal decision is to try to complete three cases per month.

Another challenge is the registration system, which in 2011 became geared to only counting direct work with the client in focus, the child, so that all parts of the investigation without the child, for example, meetings with parents, cannot be registered and financed. Meetings where solutions are to be discussed with parents can be registered, but not efforts to obtain more information about the child and family.

An inherent challenge in this work is how to gain access to more knowledge in order to do what the psychologist, Simon, calls 'completing the jigsaw puzzle of what we're examining, and doing this together between professionals'. A challenge in working with children and families is that small children are difficult to test, and using small children as informants is a dubious practice. Simon mentions that he can do more tests and call in the child and have this registered as a service that 'counts as work', but that more observations and dialogs with the families and in kindergartens, which could be helpful, are hardly feasible, as they are potentially 'overtime' for the professionals.

We followed the case of Charles, a 5-year-old boy, who was detected as having ADHD by the council psychologist and transferred to child and youth psychiatry. In the process from the visit to the home of the child, to the kindergarten and later a medical history dialog between Simon, Carl, and the mother, everyone reflects on what the case contains, and very quickly realize that the boy's mother is very vulnerable, and that the life of the child has been dramatic with family break-ups and depressive parents. They do not have much time, and accompanying them in the car between visits, we learn how they use this as a reflective space, where the method seems to be: For how long can we

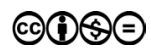


safeguard an open reflective space on the case without a diagnosis? This is thus a kind of counter effort to the task ahead of them.

In the end, they have to decide on something, and this diagnostic imperative positions them somewhat differently according to their distinct professional identities. The dialog between the two professionals in the team meeting, preparing for the ultimate 'network conference on the child', and after the first presentation to the parents, is greatly concerned with the reactions of the parents:

Simon: The mother wasn't very keen on Charles (the child) not having an ADHD
diagnosis, she would have wanted it.
The only one who was happy was Peter, the stepfather, who said: 'Phew!'
because it wasn't an ADHD diagnosis, he was relieved.
Simon: I think they had expected an ADHD diagnosis, the mother would have pre-
ferred it, it's more difficult to have to do something yourself, and therefore
we're often tempted as therapists to use diagnoses, or how shall I put it: it's
easier to say to Grandma when she calls, that it's ADHD than something to
do with the upbringing and the mother's own situation. And it's simpler, that
when they leave the meeting, well, what did they actually say, the people from
child psychiatry? One really wants to say it clearly and explain what's going
to happen.
And then when you look into the mother's background, then she could have
an ADHD diagnosis, her sister has an addiction, her father had an addiction
for a period of time, grandfather had an addiction - it could be something in
the ADHD spectrum, but now we'll have to see how the educational support
services can help, they have half a year to make an intervention before he
starts school, and they can come back with him if it doesn't work. (Fieldnotes
on case: Charles)

\section{Professional identity and meaning are challenged}

Both Simon and Carl are concerned with the outcome for the parents, and at the same time their own role in this as professionals, as they attach a great deal of meaning to the work process they have been through: did we see what there was to see? Do we have enough understanding of the case? And not least, can we avoid a disaster for this child and the family? Both professionals are concerned with the process and how to monitor it in the next meeting or conference, and observe their own work in relation to external standards (will the family be dissatisfied?) Carl explicitly safeguards their common work by stating that 'they can come back' if the work they have done does not give results. As a psychologist and a social worker, they here seem positioned equally as the performers of a monitored practice, that could go wrong at the practical level, due to their work, as well as due to a number of dimensions that they cannot influence, first of all the distress and general situation of the parents. But their words also demonstrate that subjective professional meaning is at stake.

For Simon, it is the analytical process and the methodological practice that give professional meaning. It is about being true to what he can observe and how he understands the problem, in spite of other interests, and regardless of the diagnostic imperative. For 
Carl, it is meaningful to be able to visualize and facilitate a positive social process in the future life of the child, and he is close to taking social responsibility for this child's recovery by producing a plan for the future. Carl goes on to criticize the way the parents and the kindergarten deal with the child both educationally and socially, and displays a clear interest in having some control over the process after the case has left the unit.

These two professionals can be seen as caught up in a situation where two paradoxical rationalities are present: a bureaucratic and a political, because they must also come up with a solution that can satisfy consumers/clients. Acting in accordance with both rationalities seems in this case to be nearly impossible. Either they hand out the diagnosis the mother wants, and renounce professional meaningfulness, or they stick to their analysis and risk the case bouncing back to them in half a year.

They are however part of different professional regimes and connect to the ambiguity in the field, between the humanistic and psychiatric diagnostic paradigm, in different ways. Carl is already suggesting a differentiated position, by referring to the ADHD diagnosis as a possible solution, and suggesting that they 'must wait and see' in order to gain more certainty and not rush to tell the parents that an ADHD diagnosis is dismissed. As a social worker, the professional task is seen in relation to fulfilling the 'child's best', and a diagnosis might support this.

Simon, the psychologist, in the following interview argues for the professional wisdom of letting analyses of small children remain open-ended considering the fact that they are still developing, and many things in their lives may change with new social and pedagogical support. The professional perspective is psycho-social diagnostic, which is important for Simon. This he expresses in the following network meeting with the family, the kindergarten, and the council psychologist responsible for coordinating social interventions.

They are both seeking to present professional work that is ethically and collectively identifiable for both of them as a team, and at the same time as two distinct subjective professionals, psychologist and social worker, with differing notions of the tasks. We have seen how they positioned themselves in the professional hierarchy when the whole unit was gathered at the professional conference, but here they seem to stick to the model of inter-professional work and solutions. Their solution is to decide on the diagnosis 'relational disturbance', which is seen as a soft diagnosis, but which nevertheless can be accepted in the system, and also importantly implies a social-psychological description of the family situation and presents a strong challenge to the professionals involved to act to help this family.

\section{Managing emotions and creating an invisible diagnosis}

'The Charles case', or the process in which child psychiatry arrived and intervened in the life of Charles and his family ends with a meeting, the 'network meeting', with all the parties involved: the parents and step-parents, the director and teacher from the kindergarten, the psychologist who originally referred Charles, case workers for the family, and the two professionals from the child psychiatry unit: Carl and Simon. This final network meeting will be a condensation of all the dilemmas and challenges that have been in the making, and it reveals intense emotional labor being unfolded by both professionals under extreme time pressure. The horizon for the work of the two 
professionals is now clearly the future for the child and family, to a much greater degree than the analytical assessment, which for them already belongs to the past.

The meeting starts with Simon quite bluntly stating that this is a sensitive boy who is not chronically ill or even belongs to a specific category of diseases. He then invites Carl to talk about his observations of the boy in his specific social contexts, and Carl's thorough, empathetic observations resonate with the parents and the kindergarten staff. This leads to Simon concluding that everybody around the child has to be very aware of his present situation and how he can be helped to a better social life. Then, Carl and Simon invite the kindergarten to a dialog, and slowly the meeting is changed from a court room atmosphere where professionals are to deliver judgments into a setting where all participants have to reflect on their own role in relation to their own experience of the child, their understanding of the situation, and the solutions to be provided by the professionals as experts on the child's life. The term 'relational disturbance' is briefly mentioned as a characteristic, not as a diagnosis, and medicine is never mentioned. The space for cooperation and mutual understanding seems slowly to appear through the invisibility of the diagnosis, which Simon and Carl never said would be hidden, but their practical sense seems to guide them at this crucial point.

The dialog between Simon and the kindergarten staff becomes very heated, as the kindergarten staff become confused, because they have not been preparing themselves to present ideas about the future and their own role in this. Eventually, Simon and Carl start talking about the family support, and the biological father, who is becoming more and more upset by the reaction of the educational staff, now takes an active part:

$\begin{array}{ll}\text { Father: } & \text { He'll go to school for his own sake and not because M and P and I } \\ & \text { want him to become something big, but because he wants to, and we } \\ & \text { have to find him a school that's good for him. } \\ \text { Simon: } & \text { What are your reflections on this? He looks at the mother. } \\ \text { Mother: } & \text { I can't say anything. } \\ \text { Carl: } & \text { What do you think? He looks at both the mother and Peter. } \\ \text { Mother and Peter: } & \text { Get help as soon as possible. } \\ \text { Peter: } & \text { I've talked with my friend about it, if he's sent to a special class it can } \\ & \text { easily go the wrong way, but if he's in a normal class maybe it can also } \\ & \text { go the wrong way. }\end{array}$

This sparks off a heated discussion about schools, and no longer about the psychiatric system, but on the broader context of the child, and the focus is being placed on the parents who become exceedingly upset.

Carl and Simon close the discussion by saying that now there must be an action, Carl starts to spell out what could be done and how it could be done if the council services took the initiative. The council say that they have no money, and now the emotions of the mother and biological father are aroused. Simon and Carl create some emotional space, as they ask to the parents' stance for quite some time and this finally inspires the kindergarten director, who promises to start making a plan and raising money for special support for Charles. This seems to have helped the director to reconsider the resources and the possibilities of the setting.

Simon and Carl have here performed intense emotional labor, which includes managing a variety of emotions and reactions and dynamizing the process, creating a speed 
up in outcome. The crucial outcome is the emphasis on a future timeframe at the meeting, instead of concentrating on elements of the past.

\section{Invisible emotional labor}

During the professionals' work, the processing of emotions in relation to the family and network of professionals, the people around the child stand out as vital to the way the case proceeds, and as a central way of supporting the performance of the tasks. In order to succeed with their work, the professionals have one eye on what their analysis will achieve in relation to the child, the parents and the network of relationships involving the child, and one eye on the future after the diagnosis. Standardization does however transform and influence this work in important ways: first of all by directing emotional labor towards supporting specific performances: the diagnosis, or the non-diagnosis that is being performed in relation to what it is not; and second by making emotional labor more secondary, more invisible, as a non-described working process that is not necessary in order to produce the documented performance, although indeed necessary to produce the interactive performance of finding a way forward for the network around the child. This part of the professional work becomes invisible when legitimate events in the proceedings are recorded and also in the diagnosis supported by the institution and carried over to other institutions that meet the child and family.

The work includes many meetings that break the rules of standardization and follow their own logic, since it is here that the importance of the child's relationships and social life contexts is revealed to the professionals. This forms the basis of the perceptions of those involved as the core of the work; these perceptions challenge the trend toward work processes that focus on the child as a detached entity. The parents' problems appear, and the child's problems are considered in the light of those of the parents, although formally the parents are only of relevance as informants.

The professionals are concerned with the question of whether their analysis and solution will have a positive effect for the parents and children who have to live with the problems. A professionally organized process that not only allows parents - but also, for example, the kindergarten staff - to process their emotions plays a vital role for solving the task, and also for whether it seems professionally justifiable to let others take over the case. The progression of the work process and the outcome of the case thus depend on the professionals' capacity for emotional labor not only in relation to people close to the child but also in relation to themselves and each other. If, for example, the test and results arouse much opposition, the team must stand together professionally and emotionally to enable them to share the responsibility. In this case, we see that Simon and Carl are capable of handling emotions and tolerating the fact that the network meeting might end in chaos. They have an expertise in working with emotions and can show flexibility in their work with the people they face and are partially responsible for.

But we also see that the two professionals are positioned differently by the standardization requirements for a division of labor, whereas they themselves regard the work as a joint effort where they need each other as sparring partners in the analysis. As 'process consultants', they need to be a team that can jointly maneuver the case successfully with the inclusion and processing of all the emotions it arouses and involves. In this sense, Simon and Carl's practice is effective in relation to standardization because they 
are able to drag the case out of child psychiatry and hand it over to the parties involved in the child's context.

\section{Concluding discussion}

This article illustrates how the recent reforms of psychiatry and the different forms of standardization that they imply challenge the professional paradigms that form the basis for mental health work. The increasing focus on diagnoses as a product implies a loss of legitimacy for more complex and context-sensitive assessments that are not easily reduced to scores and numbers. We see a reconstruction of what counts as knowledge and who counts the most as professionals, leading to strained social relations in the interdisciplinary team and marginalization of some of the groups. This process leads the highly skilled emotional labor in psychiatry to be made increasingly invisible.

The increasing focus on diagnosis production tends to reorient the aim of work. This narrow focus on the diagnosis is however not just implemented; it is struggled over and negotiated by the professionals, trying to secure a broader goal implying that child and families are helped to handle the problems they face, even across the institutional boundaries between psychiatry and other institutions such as municipal social administration, schools, kindergartens. As the analysis of the diagnoses team shows, it is not easy to avoid giving a diagnosis; it requires a lot of extra work, not just in relation to management and colleagues but also in relation to clients and partners who expect a diagnosis. So, this standardized measure of productivity also produces its own logic.

These results resonate well with other studies, which show how standardized bureaucratic systems in fact generate a lot of 'hidden work' in order to get the work done in a way that lives up to professional standards (e.g. Kirschhoff \& Karlsson, 2013; Vabø, 2007). But it also points at the processes of negotiation, translation, and struggles that evolve. Similar observations can be found in, for example, Dahl's studies of standardization of home care, showing that this new language and rationale is translated and resisted in different ways by the care workers (Dahl, 2009).

However, in this interdisciplinary context, we also address the impact of standardization on the construction of what counts as knowledge and the positioning of different professions. As the conference example shows the focus on correct diagnosis making, rather than on understanding the child in its context, create a framing that privileges professional preoccupation with standardized solutions, instead of a broader analysis of the unique child in its context. The conference work becomes more manageable, as some aspects are placed as minor and of less interest. At the same time, some types of professional knowledge and professions are privileged in relation to others, first and foremost psychologists. So, standardization plays an important role in reinforcing the hierarchy of professions and disciplines, and potentially creates ruptures in relations and team work. This way of working clearly upsets the balance between the social, learning, and childhood-oriented perspectives and the medical, diagnostic perspectives.

But as the analysis of the conference and teamwork underline, it is vital for professionals to make and maintain stable relations to colleagues in order to perform in standardized ways, as well as in order to fulfil professional common aims of the teams. So, while professional identities are defended, inter-professional relations are also being confirmed and maintained. Professional identities are negotiated as part of hierarchical 
rivalry, but they are also being negotiated as part of intersubjective team relations, and as part of creating the professional common goals of the unit, or big team.

In psychiatry, emotional labor is highly skilled and an integrated part of the professional regime. Our analysis illustrates how emotional labor is an important part of getting the job done, the job of assessing children and their families. But we also show how emotional labor may also be considered the core of work, as the therapeutic elements of the process are stressed.

So, we will argue that the reforms and the standardization they entail actually raise the demands for emotional labor, both in relation to colleagues, negotiating the strained collegial relations due to the quest for reconfiguration of professional hierarchies. It takes place in relation to clients and partners in the accelerated processes that is implied by the leaning of work procedures. The speeding up of the work process, the strain on solutions rather than the process, and the urge to divide work more up and to minimize team work is shown through the case. This involves formation of short-time relationship due to short-term patient pathways. And, it also takes place when the professionals try to compensate for the lack of follow-up on the 'end product', as the clients leave the psychiatric unit.

Emotional labor in psychiatry is not only increasing, but it is also made still more invisible - it does not count in the registration of outputs - and is not included as part of the evidence base for high-quality working in psychiatry. Thus, it is not recognized and does not form a basis for reflection, learning, and development, in the same way as, for example, testing and diagnostic work. Emotional labor is often tacit and undervalued, which studies of professions like nursing point out (Smith, 2012). Emotional labor is neither standardized nor easily standardizable. It involves both conscious and unconscious processes, and is highly situational. As such, it may come as no wonder that it is easily excluded, when work is described and counted through standardized measures. However, this study that explores the multifaceted features of work in psychiatry show, show the paradoxical outcomes, and point out that it is left to the professionals to make ends meet and succeed in the working process.

\section{References}

Blomberg, M. (2003). Ordering a profession. Swedish nurses meet New Public Management. Financial Accountability and Management, 19(1) 45-71. doi: http://dx.doi.org/ 10.1111/1468-0408.00163.

Bolton, S. C. (2005). Emotion management in the workplace. Palgrave, Macmillan.

Bovbjerg, K. M. et al. (2012). Nye ledelsesrationaler i det offentlige [New management rationales in the public sector]. In Kirsten Marie Bovbjerg (Ed.) Motivation og Mistillid. Effektivisering og stress på offentlige arbejdspladser [Motivation and distrust. Efficiency and stress in the puclic sector]. Copenhagen, Hans Reitzel. pp. 17-42.

Bradbury, H., N. Frost, S. Kilminster, M. Zukas (eds.) (2008): Beyond Reflective practice: New approaches to professional lifelong learning, Routledge, Leeds.

Brinkmann, S. (2010). Det diagnosticerede liv [Life according to diagnoses], Forlaget Klim, Copenhagen.

Busch, T., Johnsen, E. Klausen, K. K. Klausen, J. O. Vanebo (2005). Modernisering av offentlig sektor: Utfordringer, metoder og dilemmaer [Modernization of the public sector: challenges, methods and dilemmas]. Oslo, Universitetsforlaget. 
Chodorow, N.J. (1999). The power of feelings, New Haven and London, Yale University Press.

Christensen, K. (2012a). Towards a mixed economy of long-term care in Norway?. Critical Social Policy, 32(4), 577-596. doi: http://dx.doi.org/10.1177/0261018311435028.

Dahl, H. M. (2005). A changing ideal of care in Denmark: A different form of retrenchment. Dilemmas of Care in the Nordic Welfare State: Continuity and Change, 47-61.

Dahl, H. M. (2009). New public management, care and struggles about recognition. Critical Social Policy, 29(4), 634-654. doi: http://dx.doi.org/10.1177/0261018309341903.

Danish Regions (2008). Et styrket og udbygget akutberedskab i børne- og ungdoms psykiatrien [Enhanced and expanded emergency treatment in child and youth psychiatry].

Danish Regions (2011). Kvalitet i psykiatrien [Quality in psychiatry].

Donovan, M. (2002). Social work and therapy: Reclaiming a generic therapeutic space in child and family work. Journal of social work practice, 16, 2, 113-123. doi: http://dx.doi.org/10.1080/0265053022000033685.

Dybbroe, B. (2008). Crisis of learning, Professional knowledge and welfare in care. In Wrede, S. et al (eds.) Care Work in crisis. Reclaiming the Nordic ethos of care. Studentlitteratur. Lund.

Dybbroe, B. (2012). The meaning of work in subjective and intersubjective perspective. A daily conflict of creating and loosing meaning in elderly care. In Kamp, A \& Hvid (2012). Elderly care in transition: Management, meaning and identity at work. Copenhagen, Copenhagen Business School Press.

Evetts, J. (2011). Sociological analysis of professionalism: Past present and future. Comparative Sociology, 10, 1-37. doi: http://dx.doi.org/10.1163/156913309X421655.

Greve, C. (2003). Public sector reform in Denmark: Organizational transformation and evaluation. Public Organization Review, 3, 3, 269-280. doi: http://dx.doi.org/10.1023/ A:1025337515880.

Greve, C. (2007). Contracting for Public Services. London, Routledge.

Halford, S., Obstfelder, A. and A-T Lotheringen (2010). Changing the record: the interprofessional, subjective and embodied effect of electronic patient records. New Technology work and employment, 25, 3, 210-222. doi: http://dx.doi.org/10.1111/j.1468-005X. 2010.00249.x.

Hjort, K. E. (2001). Moderniseringen af den offentlige sektor. [Modernisation of the Public Sector] Frederiksberg: Roskilde Universitetsforlag.

Hochschild, A. R. (2003 [1983]). The Managed heart. The California University Press.

Johansen, K. S. (2005). Kultur og psykiatri: en antropologi om transkulturel psykiatri på danske hospitaler. [Culture and Psychiatry: an anthropology of transcultural psychiatry in Danish hospitals] PhD Dissertation. Institut for Antropologi. Det Samfundsvidenskabelige Fakultet Københavns Universitet, København.

Kamp, A. (2012). Meaning of work in elderly care in Denmark. Fragile reconstructions. Kamp, A. \& Hvid, H. Elderly Care in transition. Management meaning and identity at work. A Scandinavian perspective. Copenhagen: Copenhagen business school press.

Kamp, A. \& Hvid, H. (2012). Elderly care in transition: Management, meaning and identity at work. Copenhagen, Copenhagen Business School Press.

Kirschhoff, J. \& Karlsson, J. (2013). Expansion of output: Organizational misbehaviour in public enterprises. Economic and Industrial democracy, 34(1) 107-122 doi: http://dx.doi. org/10.1177/0143831X12439113.

Kleinman, A. (2012). Rebalancing academic psychiatry: why it needs to happen - and soon. British Journal of Psychiatry, 201(6), 421-422. doi: http://dx.doi.org/10.1192/bjp.bp. 112.118695.

Kröger, T. (2011). The adoption of market-based practices within care for older people: is the work satisfaction of Nordic care workers at risk?. Nordic Journal of Social Research, 2, 91-105. doi: http://dx.doi.org/10.15845/njsr.v2i0.114.

Liff, R. \& Andersson, T. (2011). Integrating or disintegrating effects of customized care: the role of professions beyond NPM. Journal of Health Organizations and Management, 25, 6, 658-676. doi: http://dx.doi.org/10.1108/14777261111178547. 
Madison, S. (2005): Critical ethnography- Method, ethics and performance, New Oaks, Sage publications.

Madsen, M. H., Hvenegaard, A. and Fredslund, E. K. (2011): Opgaveudvikling på psykiatriområdet. Opgaver og udfordringer $i$ kommunerne i relation til borgere med psykiske problemstillinger [Task development in mental health care. Tasks and challenges in municipalities with regard to citizens with mental problems]. Copenhagen, Danish Institute for Health Services Research.

Marcus, G. (1995). Ethnography in/of the world system: The emergence of Multi-Sited Ethnography. Annual Review of Anthropology, 24, 95-117.

Møllerhøj, J. (2008). On unsafe ground: the practices and institutionalization of Danish psychiatry, 1850-1920. History of Psychiatry, 19, 3, 321-337. doi: http://dx.doi.org/10.1177/ 0957154 X07081131.

Olesen, H.S., J. Wolfgang, K. Nicolls (2011). Professionalisation: the struggle within. European Journal on the education and learning of adults, 2, 1, 7-20.

Rasmussen, B (2012). New Public Management. Constructing new managerial identity in care for the elderly. In Kamp, A \& Hvid (2012). Elderly care in transition: Management, meaning and identity at work. Copenhagen, Copenhagen Business School Press.

Rasmussen, B. (2004). Between endless needs and limited resources: the gendered construction of a greedy organization. Gender, Work \& Organization, 11(5), 506-525. doi: http://dx.doi.org/10.1111/j.1468-0432.2004.00245.x.

Sahlin-Andersson, K, Bentsen, E.E., Borum, F. \& Erlingsdottir, G. (eds) (1999). Når styringsambitioner møder praksis. [When management ambitions meet practice] Copenhagen: Copenhagen Business School Press.

Selberg, R. (2013). Nursing in Times of Neoliberal Change: An Ethnographic Study of Nurses' Experiences of Work Intensification Nordic Journal of Working Life Studies, 3, 9-36.

Shore, C., Wright, S. and D. Pero (Eds.) (2011). Policy worlds. Anthropology and the analysis of contemporary power. New York: Berghahn Books.

Simonsen, E. and B. Møhl (2010). Grundbog i Psykiatri [A Reader in psychiatry]. Copenhagen, Hans Reitzels Forlag.

Smith, D. (2005). Institutional ethnography- A sociology for people, Altamira Press, The Gender Lense, Lanham.

Smith, P. (2012). The emotional labour of nurses revisited. Can nurses still care? Basingstoke, Palgrave MacMillan.

Theodosius, C. (2008). Emotional labour in health care. The unmanaged heart of nursing. London, Routledge.

Theodosius, C. (2012). Feeling a feeling in emotion management. In: Hunt, A, Walby, K \& Spencer, D. (eds.). Emotions Matter: A Relational Approach to Emotions, Torronto, University of Torronto Press. pp. 63-85.

Timmermans, Stefan \& Marc Berg (2003). The Gold Standard. The Challenge of Evidence-Based medicine and Standardization in Health Care. Philadelphia, Temple University Press.

Timmermans, Stefan \& Steven Epstein (2010). A World of Standards but not a Standard World: Toward a Sociology of Standards and Standardization. Annual Review of Sociology 36, 69-89. doi: http://dx.doi.org/10.1146/annurev.soc.012809.102629.

Vabø, M. (2007). Organisering for velferd. Hjemmetjenesten $i$ en styringsideologisk Brytningstid. [Organizing for welfare. Elderly care in times of conflicting managerial paradigms] NOVA Rapport 22/2007.

Wrede, S. et al (eds.) (2008). Care Work in crisis. Reclaiming the Nordic ethos of care. Studentlitteratur. Lund

Zukas, M. \& Kilminster, S. (2012). “Learning to practise, practising to learn: doctors' transitions to new levels of responsibility," in Hager, P., Lee, A. and Reich, A. (Eds), Practice, Learning, Change: Practice-theory Perspectives on Professional Learning, Springer, Dordrecht. 